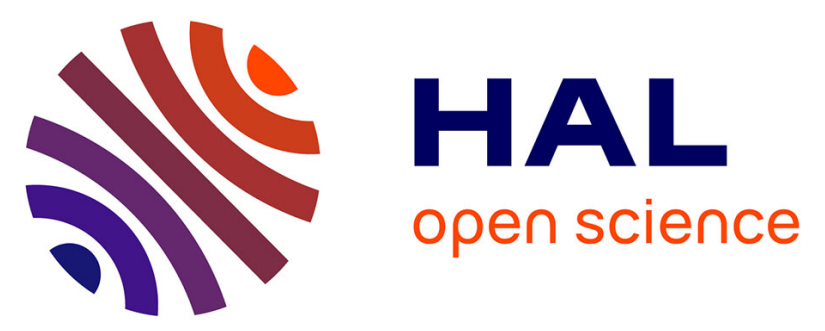

\title{
Conditions to minimize soft single biomolecule deformation when imaging with atomic force microscopy
}

Christian Godon, Jean-Marie Teulon, Michaël Odorico, Christian Basset, Matthieu Meillan, Luc Vellutini, Shu-Wen W Chen, Jean-Luc Pellequer

\section{- To cite this version:}

Christian Godon, Jean-Marie Teulon, Michaël Odorico, Christian Basset, Matthieu Meillan, et al.. Conditions to minimize soft single biomolecule deformation when imaging with atomic force microscopy. Journal of Structural Biology, 2017, 197 (3), pp.322 - 329. 10.1016/j.jsb.2016.12.011. hal-01497664

\section{HAL Id: hal-01497664 \\ https://hal.science/hal-01497664}

Submitted on 13 Jan 2021

HAL is a multi-disciplinary open access archive for the deposit and dissemination of scientific research documents, whether they are published or not. The documents may come from teaching and research institutions in France or abroad, or from public or private research centers.
L'archive ouverte pluridisciplinaire HAL, est destinée au dépôt et à la diffusion de documents scientifiques de niveau recherche, publiés ou non, émanant des établissements d'enseignement et de recherche français ou étrangers, des laboratoires publics ou privés. 


\title{
Conditions to minimize soft single biomolecule deformation when imaging with atomic force microscopy
}

\author{
Christian Godon ${ }^{\mathrm{a}}$, Jean-Marie Teulon ${ }^{\mathrm{b}, \mathrm{c}, \mathrm{d}}$, Michael Odorico ${ }^{\mathrm{e}}$, Christian Basset ${ }^{\mathrm{f}}$, Matthieu Meillan ${ }^{\mathrm{g}, \mathrm{h}}$, \\ Luc Vellutini $^{\mathrm{g}, \mathrm{h}}$, Shu-wen W. Chen ${ }^{\mathrm{i}}$, Jean-Luc Pellequer ${ }^{\mathrm{b}, \mathrm{c}, \mathrm{d}, *}$
}

${ }^{a}$ CEA, BIAM, LBDP, F-13108 Saint Paul lez Durance, France

${ }^{\mathrm{b}}$ Univ. Grenoble Alpes, IBS, F-38044 Grenoble, France

${ }^{\mathrm{c}} \mathrm{CNRS}, \mathrm{IBS}, \mathrm{F}-38044$ Grenoble, France

${ }^{\mathrm{d}}$ CEA, IBS, F-38044 Grenoble, France

e ICSM-UMR5257 CEA/CNRS/UM2/ENSCM, F-30207 Bagnols sur Cèze, France

${ }^{\mathrm{f}} \mathrm{CEA}, \mathrm{BIG}, \mathrm{F}-38054$ Grenoble, France

${ }^{\mathrm{g}}$ Univ. Bordeaux, ISM, UMR 5255, F-33400 Talence, France

${ }^{\mathrm{h}}$ CNRS, ISM, UMR 5255, F-33400 Talence, France

i 478 rue Cyprien Jullin, 38470 Vinay, France

\section{A R T I C L E I N F O}

\section{Article history:}

Received 27 June 2016

Received in revised form 6 December 2016

Accepted 21 December 2016

Available online 23 December 2016

\section{Keywords:}

AFM topography

Single molecule deformation

Mica

Self-assembled monolayers

Peakforce tapping

Tobacco mosaic virus

\begin{abstract}
A B S T R A C T
A recurrent interrogation when imaging soft biomolecules using atomic force microscopy (AFM) is the putative deformation of molecules leading to a bias in recording true topographical surfaces. Deformation of biomolecules comes from three sources: sample instability, adsorption to the imaging substrate, and crushing under tip pressure. To disentangle these causes, we measured the maximum height of a well-known biomolecule, the tobacco mosaic virus (TMV), under eight different experimental conditions positing that the maximum height value is a specific indicator of sample deformations. Six basic AFM experimental factors were tested: imaging in air (AIR) versus in liquid (LIQ), imaging with flat minerals (MICA) versus flat organic surfaces (self-assembled monolayers, SAM), and imaging forces with oscillating tapping mode (TAP) versus PeakForce tapping (PFT). The results show that the most critical parameter in accurately measuring the height of TMV in air is the substrate. In a liquid environment, regardless of the substrate, the most critical parameter is the imaging mode. Most importantly, the expected TMV height values were obtained with both imaging with the PeakForce tapping mode either in liquid or in air at the condition of using self-assembled monolayers as substrate. This study unambiguously explains previous poor results of imaging biomolecules on mica in air and suggests alternative methodologies for depositing soft biomolecules on well organized self-assembled monolayers.
\end{abstract}

(c) 2016 Elsevier Inc. All rights reserved.

\section{Introduction}

Atomic Force Microscopy (AFM) belongs to the family of near-field scanning microscopy. The atomic force microscope was developed in 1986 (Binnig et al., 1986) just four years after the appearance of the scanning tunneling microscope (Binnig et al., 1982). Unlike photonic or electronic microscopy, AFM is essentially a surface sensor with nanometer resolution in a lateral dimension (Pfreundschuh et al., 2014) and near-angstrom resolution in height (Schabert and Engel, 1994). In the simplest mode, known as constant force mode (and often called contact mode), the cantilever

* Corresponding author at: IBS, 71 avenue des Martyrs, CS 10090, F-38044 Grenoble Cedex 9, France.

E-mail address: jlpellequer@cea.fr (J.-L. Pellequer). is permanently in contact with the surface of the sample. The presence of any molecule perturbs the cantilever, which in turn modifies the deflection of a laser beam. An electronic feedback loop is then used to move the piezoelectric stage up or down so that the imaging force remains constant. The upward or downward motion of the piezoelectric stage gives rise to a topographic 2D image of the deposited sample. The contact mode was the first imaging mode employed (Marti et al., 1987), but soon encountered difficulties in its application to isolated soft biomolecules, which were insufficiently attached to the substrate and were sensitive to the lateral shear force provoked by the moving tip. In order to reduce these lateral forces, an oscillating mode (called tapping mode, $\mathrm{TAP}^{1}$ )

\footnotetext{
${ }^{1}$ Abbreviations: TAP, tapping mode; PFT, PeakForce tapping; SAM: Self-assembled monolayers; TMV, Tobacco mosaic virus.
} 
was devised in which the cantilever is only temporarily in contact with the sample (Zhong et al., 1993). In TAP, the cantilever vibrates at its fundamental resonant frequency in free space. When approaching the sample surface, the amplitude of oscillation decreases and a feedback loop is used to maintain a user-defined amplitude (set point). Depending on the AFM set-up in TAP, the imaging force (load) is usually above several hundred piconewtons (pNs) (San Paulo and Garcia, 2001). Although the application of tapping mode has been very successful for imaging soft biomolecules, it was suggested in the mid 1990s that to reduce biological sample deformation, new developments should aim at off-resonance tapping mode schemes for controlling the maximum peak force on the sample (Spatz et al., 1995). Recently, several off-resonance tapping modes have been developed including a mode known as PeakForce tapping (PFT) (Kaemmer, 2011). In this mode, scanning speeds and the number of pixels per image are similar to TAP and the physical contact between the cantilever and the sample is also intermittent. Whereas in the TAP mode the cantilever oscillates at its resonance frequency (several tens of $\mathrm{kHz}$ ), in PFT, the oscillation of the cantilever is not at its resonance frequency (an initial fixed value of $2 \mathrm{kHz}$ ). It follows that, with the PFT mode, for the same scan rate the energy dissipation per pixel is substantially less (10-50-fold) than in tapping mode. Furthermore, in the PFT mode, the feedback loop attempts to keep the peak load force constant instead of the amplitude as in the tapping mode. Considering these last two points, the PFT mode seems to be, in comparison with the TAP mode, a good compromise to protect sample from depth deformation.

The imaging load is an expected cause of soft sample deformation which translates into a major reduction in the apparent height of imaged molecules. The mechanical deformation of proteins has been studied using the force curve mode of AFM. Results on lysozyme and carbonic anhydrase II revealed the viscoelastic property of single proteins under indentation, but without noticing full denaturation (Radmacher et al., 1994; Afrin et al., 2005). Nevertheless, numerous studies demonstrated difficulties in obtaining accurate topography of biomolecules such as proteins (Umemura et al., 1996; Bergkvist et al., 1998; Cheung and Walker, 2008) and nucleic acids (Moreno-Herrero et al., 2003; Yang et al., 2007). To fully exploit the capacity of AFM to produce high resolution topographical surfaces of single biomolecules, as required in three-dimensional atomic reconstruction (Czajkowsky and Shao, 2009; Trinh et al., 2012; Chaves et al., 2014; He et al., 2016), it is critical to evaluate all sources of errors in topographical surface measurement accuracy.

However, the origin of errors in height measurements are very difficult to determine due either to the lack of proper internal calibration systems or the lack of alternative techniques able to measure such small height variations $(<1 \mathrm{~nm})$. To disentangle physico-chemical contributions influencing accurate measurement of topographical surfaces, we devise an experiment which aims at measuring the known height of a virus under various experimental conditions. Tobacco Mosaic Virus (TMV), usually described as a rod-like shape particle of about $300 \mathrm{~nm}$ in length, is one of the few model systems to thrive on more than 100 years across scientific disciplines such as virology, immunochemistry, biochemistry, biophysics, and nanosciences (Creager, 2002). TMV is a very stable biological system at room temperature both in air and in liquid and therefore is suitable for studying height measurement in different imaging environments. TMV particles have been extensively characterized by electron microscopy, X-ray crystallography (Creager, 2002; Namba et al., 1989) and atomic force microscopy (Horne et al., 1976; Namba and Stubbs, 1986; Zenhausern et al., 1992); in addition, an atomic-resolution crystal structure is available (Fig. 1, PDB code 1VTM (Pattanayek and Stubbs, 1992)) which eases image processing developments (Trinh et al., 2011; Chen et al., 2016). Using a 2D topography reconstruction of a TMV sec-

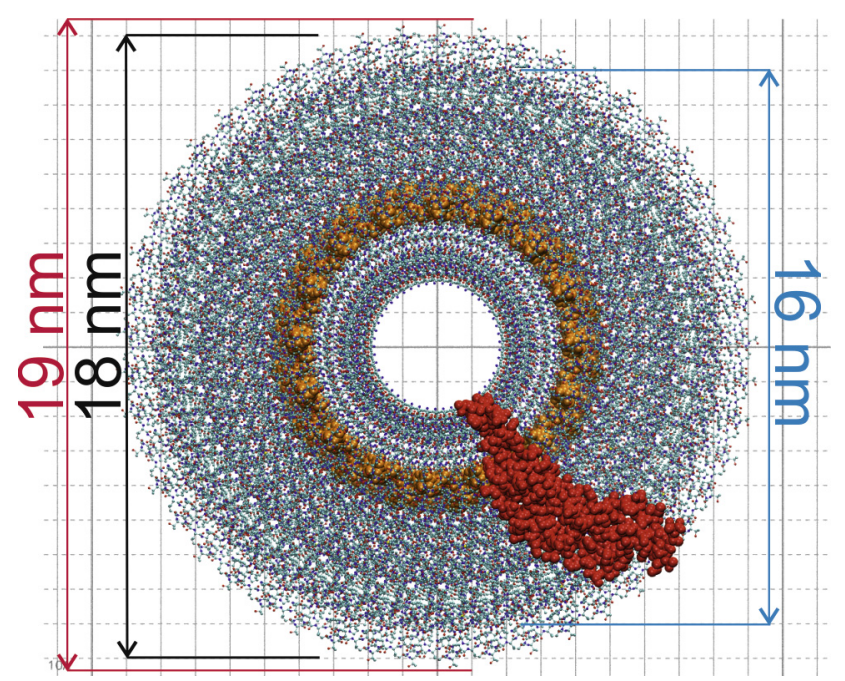

Fig. 1. Axial representation of the three-dimensional structure of tobacco mosaic virus (TMV) particle based on PDB code 1VTM (Pattanayek and Stubbs, 1992). Single strand RNA is shown in orange color whereas protein atoms are displayed using a colored atom scheme with cyan for carbon, blue for nitrogen, red for oxygen, and yellow for sulfur. The central hole in the particle is about $4 \mathrm{~nm}$ in diameter and does not contain any RNA atoms. A single subunit of TMV is highlighted in red (the TMV is built of about 2130 subunits). A background ruler is drawn in gray where one unit square has a size of $1 \times 1 \mathrm{~nm}^{2}$. From this view, we obtain the largest diameter of the particle which is $19 \mathrm{~nm}$. It is also possible to distinguish a hard core of the TMV particle ( $16 \mathrm{~nm}$ diameter) which basically excludes the last 5 C-terminal residues of each protein subunit. Image drawn using VMD (Humphrey et al., 1996).

tion based on the crystallographic coordinates, a maximum TMV diameter (height) value of $19.02 \pm 0.01 \mathrm{~nm}$ has been deduced (Chen et al., 2013). To illustrate the challenge of topography measurement on single isolated molecules, TMV particles have been imaged by AFM using various experimental conditions and imaging modes (Schabert and Rabe, 1996; Falvo et al., 1997; Maeda, 1997; Drygin et al., 1998; Knez et al., 2004; Zhao et al., 2008) and reported TMV heights range from 12 to $23 \mathrm{~nm}$. A study of various imaging substrates has been performed on mica, gold, HOPG, and SAM (Knez et al., 2004). However, no significant statistical analyses have been performed in these studies and no systematic study has been conducted to determine the causes of these height measurement variations.

In this work, we used the AFM-measured TMV height value as an indicator of TMV deformation and thus inaccurate topography reporting. Currently, we are focusing on three factors which may contribute to inaccurate height determination by AFM, namely the imaging mode, the substrate material and the imaging environment. The first factor provokes height loss when the number of tipsample contacts per area increases. The second factor can induce structural deformation of the sample depending on the number of negative-positive charges at the surface of the substrate, allowing an increase in adsorption of the sample. The third factor, whether the measurement is carried out in air or in water, can attenuate sample-substrate binding (therefore the deformation of the molecule) or the interaction between the tip and the sample. Therefore, we designed a series of experiments with two AFM imaging modes (TAP and PFT), two different substrate materials (mica and acid-terminated self-assembled monolayers, SAM$\mathrm{COOH}$ ), and two imaging environments (ambient and liquid). The results were obtained from several batches of imaged virus, from three independents experimentations spread over three years, and performed in two geographical locations with two different atomic force microscopes. Applications of such analysis encompass the determination of "ideal" conditions (substrate, imaging mode, environment) required to perform a comparative evaluation of 
native or mutant biomolecules in presence or absence of stress, similarly to what was made regarding substrates for evaluating radiation damages on biological samples (Costa et al., 2016).

\section{Material and methods}

\subsection{Experimental setups}

The PeakForce Tapping (PFT) and Tapping (TAP) modes were set in both instruments of Multimode 5 and 8 (named multimode $n^{\circ} 1$ and $n^{\circ} 2$, respectively) equipped with a NanoScope $V$ controller, a vertical engage J-scanner $(120 \mu \mathrm{m}$ scan size) and NanoScope version 8 software (Bruker, Santa Barbara, CA). In our three experiments, calibration of the Z-piezoelectric ceramic was performed each time before to beginning TMV height measurement. Accurate height measurement implies a proper calibration of the Z-piezoelectric ceramic. The scanning mechanism of the two instruments were calibrated in the $\mathrm{Z}$ direction with the so-called H8 calibrator provided by the manufacturer (H8, NanoWorld, Neuchatel, Switzerland). The nominal well depth of the holes etched inside silicon of the $\mathrm{H} 8$ calibrator was reported as $7.3 \mathrm{~nm}$ and multimode $n^{\circ} 2$ has been calibrated for that value (calibration A). A different calibration has been performed on multimode $n^{\circ} 2$ for dataset 2014 when the target calibration value was set at $8 \mathrm{~nm}$ instead of $7.3 \mathrm{~nm}$ (calibration B). MFMA and MTFML-V2 probe holders (Bruker, Santa Barbara, CA) were adopted for imaging TMV particles in air and in liquid, respectively. Various tested cantilever tips (Bruker, Camarillo, CA) are listed in Table 1 with their characteristics.

PeakForce tapping mode in air (ambient) or in liquid (pure water) was used with the automated ScanAsyst mode which includes an average set-point of $0.06 \mathrm{~V}$ and a peakforce ramp of 20-40 nm. In ScanAsyst, gain values were automatically adjusted, except for the scan rate which was kept at $1 \mathrm{~Hz}$. A target physical pixel size of about $1 \mathrm{~nm}$ was pursued (often with a scan size of 1.1 or $1.7 \mu \mathrm{m}$ with 1024 pixels per line, or a scan size of $0.5 \mu \mathrm{m}$ with 512 pixels per line). We estimate the average peak force when imaging to be about $600 \mathrm{pN}$ depending on the cantilever and the deflection sensitivity.

Tapping mode measurements were recorded at a frequency of $\sim 1 \mathrm{~Hz}$ along the scanning line. The oscillation amplitude of the cantilever tip was on average about $20 \mathrm{~nm}$. The average cantilever driving amplitude was $0.04 \mathrm{~V}$ while the average setpoint values were about $0.15 \mathrm{~V}$ and were systematically adjusted to minimize the interaction between the tip and the probed surface (San Paulo and Garcia, 2000). The ratio of the vibration amplitude after engagement to the free amplitude before engagement was about $70 \%$ which allowed us to estimate the imaging force of about 200 pN (San Paulo and Garcia, 2001). All experiments were carried out at RT in air with humidity around 30\%. Similarly to PFT, a physical pixel size of $1 \mathrm{~nm}$ was pursued. The roughness (root-meansquare) of the two different substrate materials was about
$0.5 \mathrm{~nm}$ for mica and about $0.9 \mathrm{~nm}$ for acid-terminated SAM (SAM-COOH).

TMV deposited on Mica for AFM imaging in liquid or in air: $5 \mu \mathrm{l}$ of $\mathrm{NiCl}_{2}(10 \mathrm{mM})$ was deposited on the freshly cleaved mica, the mica was placed in a covered dish, and after $10 \mathrm{~min}$ and was dried under a nitrogen stream. Then, we deposited $5 \mu$ of TMV solution ( $20 \mathrm{ng} / \mu \mathrm{l}$ in pure water). The mica was placed in a covered dish with a wet piece of filter paper to keep the liquid from evaporating and, and TMV was allowed to bind on the mica substrate for $1 \mathrm{~h}$. After this incubation period, we rinsed the sample twice by dipping it into deionized water for $5 \mathrm{~s}$ to remove unbound TMV. For AFM imaging in water, a drop of deionized water was left on the mica and the sample was mounted on the AFM scanner. Before AFM imaging in air, the sample was dried by keeping it in a vacuum desiccator for $1 \mathrm{~h}$. TMV was deposited on acid-terminated-SAM for AFM imaging in liquid: SAMs provide molecularly defined platforms for the control of the surface chemistry of materials in the fields of biotechnology (Ramin et al., 2012, 2015). Functionalized self-assembled monolayers were provided by the laboratory of Dr. B. Bennetau, ISM Univ. Bordeaux. The acid-terminated SAMs were grafted on silicon wafer according the previously published procedure (Meillan et al., 2014). TMV was immobilized with the NHS-EDC chemistry. Before crosslinking, SAM-COOH was rinsed twice with ethanol and deionized water. $100 \mu \mathrm{l}$ of acetate buffer (10 mM, pH 4.5) was deposited on SAM-COOH, and then placed in a covered dish, and after $10 \mathrm{~min}$ was dried under nitrogen stream. $100 \mu \mathrm{l}$ of NHS $(11.5 \mathrm{mg} / \mathrm{ml})$ - EDC $(75 \mathrm{mg} / \mathrm{ml})$ crosslinker was deposited on SAM-COOH, and after 15 min the sample was rinsed twice by dipping it into deionized water for $5 \mathrm{~s} .50 \mu \mathrm{l}$ of TMV solution $(1 \mu \mathrm{g} / \mu \mathrm{l}$ in water) was deposited on SAM-COOH. The monolayer was placed in a covered dish with a wet piece of filter paper for $1 \mathrm{~h}$. The sample was rinsed twice by dipping it into deionized water for $5 \mathrm{~s}$, a drop of deionized water was left and the sample was mounted on the AFM scanner.

TMV deposited on SAM-COOH for AFM imaging in air: the monolayer was rinsed twice with ethanol and deionized water, and $50 \mu \mathrm{l}$ of TMV solution ( $400 \mathrm{ng} / \mu \mathrm{l}$ in water) was deposited. The SAM-COOH was placed in a covered dish with a wet piece of filter paper for $1 \mathrm{~h}$. The sample was rinsed twice by dipping it into deionized water for $5 \mathrm{~s}$ and the sample was dried by keeping it in a vacuum desiccator for $1 \mathrm{~h}$.

\subsection{Image processing and data analysis}

Tilts in raw images were corrected by a plane fit using the "Remove Polynomial background" function with a first degree polynomial in Gwyddion (Nečas and Klapetek, 2012). Subsequently, a line flattening was performed using the "level rows using intersecting lines" function with a thickness of 5 pixels. For certain AFM images obtained in liquid condition, stripe noise was removed using DeStripe (Chen and Pellequer, 2011). Next, a subimage containing a single TMV virus was cropped from the flat-

Table 1

Characteristics of cantilevers used in this study.

\begin{tabular}{|c|c|c|c|c|c|c|}
\hline Cantilever & Tip & Geometry & $\mathrm{R}_{\mathrm{tip}}(\mathrm{nm})$ & $\mathrm{F}_{0}(\mathrm{kHz})$ & $\mathrm{k}(\mathrm{N} / \mathrm{m})$ & $\mathrm{L}_{0}(\mu \mathrm{m})$ \\
\hline MLCT_D & $\mathrm{Si}_{3} \mathrm{~N}_{4}$ & Triangle & 20 & 15 & 0.03 & 225 \\
\hline MLCT_E & $\mathrm{Si}_{3} \mathrm{~N}_{4}$ & Triangle & 20 & 38 & 0.1 & 140 \\
\hline MLCT_F & $\mathrm{Si}_{3} \mathrm{~N}_{4}$ & Triangle & 20 & 125 & 0.6 & 85 \\
\hline MPP22220 & $\mathrm{Si}$ & Rectangle & 8 & 40 & 0.9 & 225 \\
\hline SNL_A & $\mathrm{Si}$ & Triangle & 2 & 65 & 0.35 & 120 \\
\hline
\end{tabular}

$\mathrm{F}_{0}$ represents nominal resonant frequency.

$\mathrm{K}$ is the nominal spring constant.

$\mathrm{L}_{0}$ denotes the nominal length.

$\mathrm{R}_{\mathrm{tip}}$ symbolizes the nominal tip radius. 
tened image with a size of $128 \times 128$ pixels. The net height of TMV particle was calculated as the difference between the maximum height of TMV particles and that of the substrate alone. The maximum height of TMV particle was calculated as an averaged height over the top $10 \%$ of the selected pixels whose intensity is greater than $12 \mathrm{~nm}$. The remaining pixels of the image were left for calculating the maximum height of the substrate (background). The detailed procedures have been described elsewhere (Chen et al., 2013). Height values are presented with their averages and standard deviations.

\section{Results}

Height measurement in AFM corresponds to the translation of z-piezo movements. These movements are related to the feedback of imaging mode and depend on the imaging conditions. To ensure that these z-translations are accurate, we performed height measurement experiments on the $\mathrm{H} 8$ calibrator which has been used during the z-calibration of the scanner at the beginning of each experiment (see methods). Measured values of H8 using two different imaging modes (PFT and TAP) and two environments (air and liquid) are shown in Table 2. After a global bow flattening followed by a polynomial flattening (order 3) using SPIP, height values of $\mathrm{H} 8$ were obtained using the peak-to-peak distance of the histogram height distribution (one peak for background and another for foreground). The largest height variation in these four acquisition modes on $\mathrm{H} 8$ is about $0.5 \mathrm{~nm}$. No significant variation is found when varying the imaging mode or imaging environment.

Over the last three years, we evaluated the robustness of TMV height measurements using three different experimenters with three different TMV preparations and with two different instruments on two geographical locations. It should also be added that samples were imaged with at least three different regions in each sample. Height values of TMV particles are reported in Table 3. Values are obtained on cropped images of TMV to facilitate an automated computation of height (Fig. 2, see methods). Values are presented as average \pm standard deviation. The number of

Table 2

The results of measuring the H8 standard height ${ }^{\mathrm{a}}$ from four experimental setups. ${ }^{\mathrm{b}}$

\begin{tabular}{lll}
\hline Environment & PFT & TAP \\
\hline AIR (ambient) & $7.51 \pm 0.09$ & $7.41 \pm 0.37$ \\
LIQUID (water) & $7.38 \pm 0.49$ & $6.99 \pm 0.59$
\end{tabular}

a The nominal depth value used for calibrating scanners is $7.3 \mathrm{~nm}$.

b Obtained on Multimode $n^{\circ} 2$ with calibration A.
TMV particles used to compute the statistics is shown in Table 3. It should be emphasized that each TMV height measure is not a single measure but a global measure of a maximum height of TMV pixels minus the maximum height of image background (see methods).

Despite minor variations, tendencies concerning imaging in air are strictly conserved: height values on mica are always lower than those on SAM-COOH (PFT ${ }_{2015} \mid$ MICA-15.8 nm vs SAM-COOH $19.7 \mathrm{~nm} \mid ;$ TAP $_{2015}$ |MICA-15.7 nm vs SAM-COOH-18.4 nm|), and this is also true for dataset 2013 and 2014. In liquid, this height reduction is abrogated ( PFT $_{2015}$ MICA-18.4 nm vs SAM-COOH$18.5 \mathrm{~nm}$; TAP $_{2015}$ |MICA-17.3 nm vs SAM-COOH-17.5 nm|). When comparing PFT and TAP mode with the same substrate, TMV height values are systematically lower with TAP than PFT in air $\left(\mathbf{P F T}_{\mathbf{2 0 1 5}} \mid\right.$ SAM-COOH-19.7 nm| vs TAP $_{\mathbf{2 0 1 5}}$ |SAM-COOH-18.4 nm|; and similarly with dataset 2013 and 2014) and in liquid (PFT 2015 $_{\text {|MICA- }}$ $18.4 \mathrm{~nm} \mid$ vs $\mathbf{T A P}_{2015}|\mathrm{MICA}-17.3 \mathrm{~nm}|$ and $\mathbf{P F T}_{2015}$ |SAM-COOH-18. $\mathrm{nm} \mid$ vs $\mathbf{T A P}_{\mathbf{2 0 1 5}}$ (SAM-COOH-17.5 nm|). Furthermore, in air these variations in height between PFT and TAP modes are greater on $\mathrm{SAM}-\mathrm{COOH}(>1 \mathrm{~nm})$ than on mica $(<1 \mathrm{~nm})$. When comparing mica and SAM-COOH substrates in the same imaging environment and imaging mode, it should be noted that the standard deviation on mica is, except for one case, lower than that on SAM-COOH. Because it is known that height values depend on the leveling tools used to flatten images, three different flattening methods in various programs have been tested (Nanoscope from Bruker, SPIP from Image Metrology, and Gwyddion). Using the same TMV height measurement procedure, no significant differences in TMV height values were found when flattened with different methods (data not shown).

\section{Discussion}

Limitations in application of AFM-generated topographical surfaces of single isolated biomolecules in structural biology are partly due to deformation of samples. The major source of deformation comes from the tip broadening effect (tip convolution) which portrays imaged molecules much larger than reality. This limitation can be tackled using image reconstruction tools (Villarrubia, 1997). However, the max height of imaged molecules is not impacted by such tip-convolution effects and thus will not be dealt with further in this study. The second suspected source of deformation in topographical surfaces is tip-sample interactions (crushing effect). Because of such a putative effect, topographical surfaces are deemed unreliable, limiting further exploitation such as atomic reconstruction of protein structures (Scheuring et al., 2007; Trinh

Table 3

TMV height measurement reproducibility.

\begin{tabular}{|c|c|c|c|c|c|}
\hline Environment & Substrate $^{a}$ & Imaging Mode $\mathrm{e}^{\mathrm{b}}$ & $\begin{array}{l}\text { TMV height }(\mathrm{nm}) \\
\text { Dataset } 2015^{\mathrm{c}}\end{array}$ & $\begin{array}{l}\text { TMV height }(\mathrm{nm}) \\
\text { Dataset } 2014^{\mathrm{d}}\end{array}$ & $\begin{array}{l}\text { TMV height }(\mathrm{nm}) \\
\text { Dataset } 2013^{\mathrm{e}}\end{array}$ \\
\hline Air & $\begin{array}{l}\text { MICA } \\
\text { SAM }\end{array}$ & $\begin{array}{l}\text { PFT } \\
\text { TAP } \\
\text { PFT } \\
\text { TAP }\end{array}$ & $\begin{array}{l}15.85 \pm 0.37\left(\mathrm{~N}_{\text {crop }}=47\right)^{\mathrm{f}} \\
15.78 \pm 0.35\left(\mathrm{~N}_{\text {crop }}=29\right) \\
19.73 \pm 1.47\left(\mathrm{~N}_{\text {crop }}=18\right) \\
18.46 \pm 1.17\left(\mathrm{~N}_{\text {crop }}=16\right)\end{array}$ & $\begin{array}{l}18.48 \pm 0.70\left(\mathrm{~N}_{\text {crop }}=30\right) \\
17.90 \pm 0.67\left(\mathrm{~N}_{\text {crop }}=31\right) \\
19.58 \pm 0.73\left(\mathrm{~N}_{\text {crop }}=23\right) \\
18.47 \pm 0.52\left(\mathrm{~N}_{\text {crop }}=20\right)\end{array}$ & $\begin{array}{l}16.80 \pm 0.24\left(\mathrm{~N}_{\text {crop }}=11\right) \\
15.95 \pm 0.08\left(\mathrm{~N}_{\text {crop }}=15\right) \\
19.14 \pm 0.33\left(\mathrm{~N}_{\text {crop }}=13\right) \\
18.13 \pm 0.50\left(\mathrm{~N}_{\text {crop }}=21\right)\end{array}$ \\
\hline Liquid & $\begin{array}{l}\text { MICA } \\
\text { SAM }^{\mathrm{g}}\end{array}$ & $\begin{array}{l}\text { PFT } \\
\text { TAP } \\
\text { PFT } \\
\text { TAP }\end{array}$ & $\begin{array}{l}18.42 \pm 0.19\left(\mathrm{~N}_{\text {crop }}=28\right) \\
17.31 \pm 0.23\left(\mathrm{~N}_{\text {crop }}=19\right) \\
18.55 \pm 1.38\left(\mathrm{~N}_{\text {crop }}=6\right) \\
17.50 \pm 1.02\left(\mathrm{~N}_{\text {crop }}=28\right)\end{array}$ & & \\
\hline
\end{tabular}

\footnotetext{
a MICA for muscovite mica and SAM for self-assembled monolayers.

b PFT for PeakForce Tapping and TAP for Tapping.

c Dataset obtained on Multimode $n^{\circ} 2$ with calibration A. Ncrop is the number of cropped isolated virus used for height measurements.

d Dataset obtained on Multimode $n^{\circ} 2$ with calibration B and MPP22220 cantilevers.

e Dataset obtained on Multimode ${ }^{\circ} 1$ with calibration A and MPP22220 cantilevers.

${ }^{f}$ See methods for TMV height measurement principles.

g TMV were covalently coupled to SAM layers.
} 


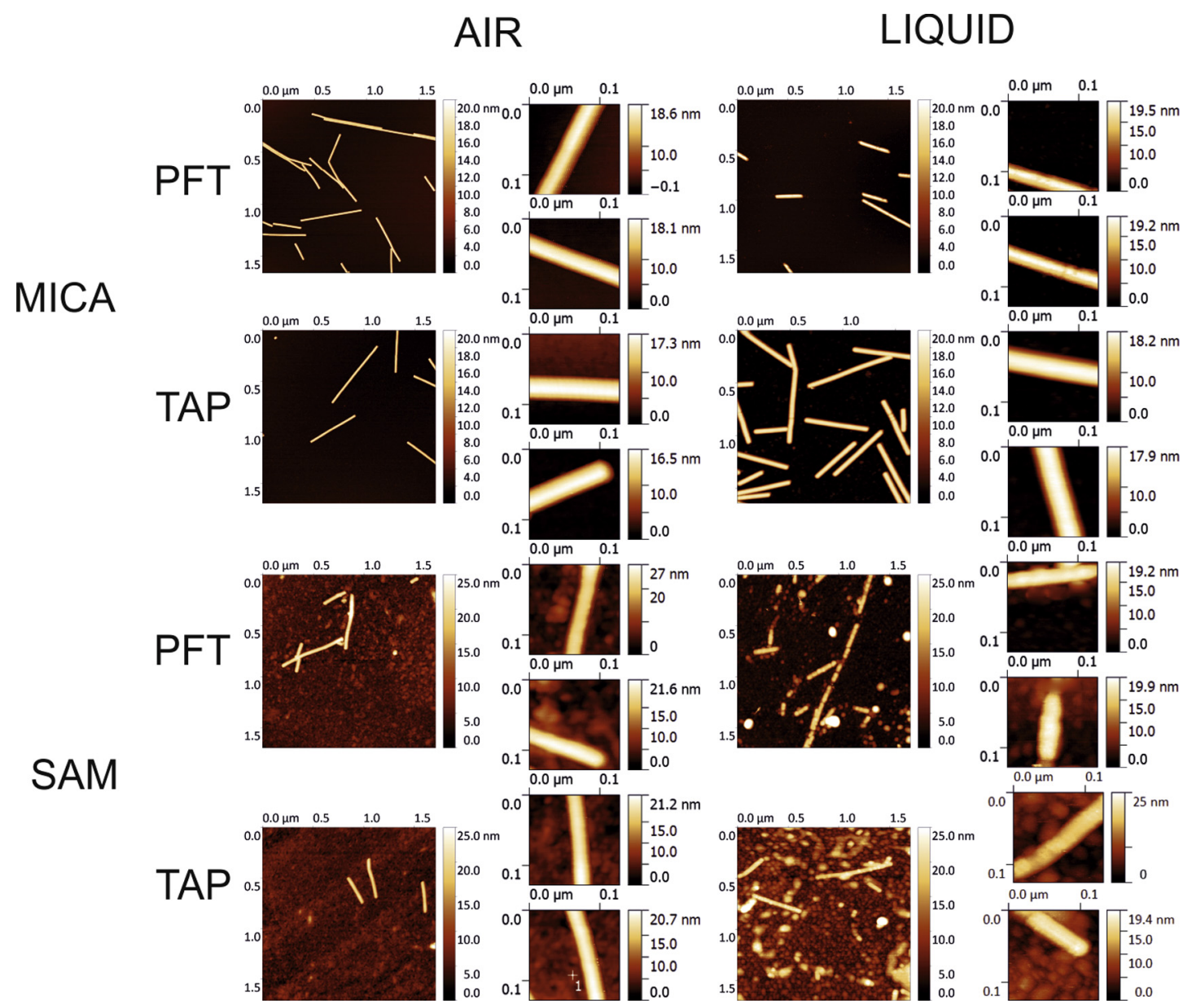

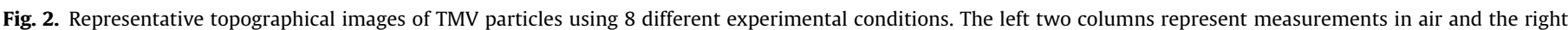

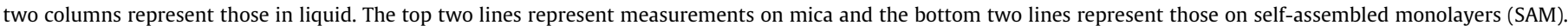

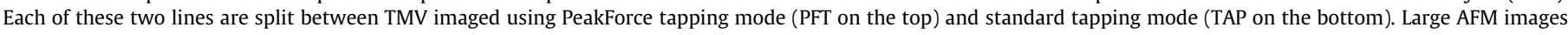

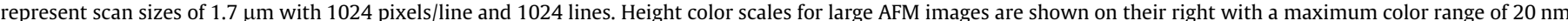

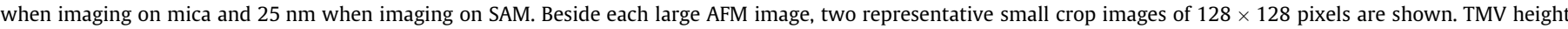

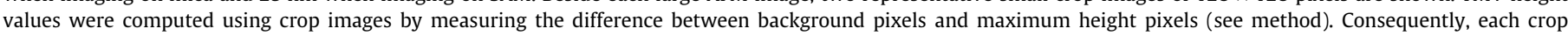
provides not a single net height value but an average net height value.

et al., 2012; Chaves and Pellequer, 2013). To our knowledge, no statistical comparative study has been performed on soft biological molecules using various AFM imaging conditions relating obtained topography with sample deformation.

In an attempt to reduce bias due to the experimenter, environmental conditions and AFM instruments, it was decided to repeat measurements in different laboratory locations, with different AFM instruments, different experimenters, and different cantilevers. These measurements lasted over the course of three years. Overall, TMV height values presented in Table 3, albeit with some differences, consistently lead to similar conclusions when comparing TAP imaging versus PFT imaging or when comparing a stiff and highly charged substrate (mica) versus a soft and moderately charged substrate (SAM). In our study we have focused on three experimental parameters: imaging substrate (mica or SAM), imaging environment (air or liquid), and the imaging mode (Tapping or PeakForce tapping) representing eight different experimental conditions. It should be emphasized that each measurement present in Table 3 corresponds to several thousands of pixels (see height measurement method). There are, of course, several additional parameters that could have been tested such as the cantilever stiffness, imaging load within an imaging mode, imaging resolution, calibration mode, and so on. However, the combinatorial explosion of these parameters prevents a reasonable statistical study of all of them. Nevertheless, we have for instance used several cantilevers in our study and tried to look at possible biases when using soft versus stiff cantilevers or small versus large tip radius. In particular, due to the difference in sharpness between MLCT and SNL cantilevers, an impact on TMV height values was expected (Zenhausern et al., 1993). However, despite the limited number of measurements performed in our study per cantilever, we have found no consistent or systematic bias on TMV height values, and consequently, all height values obtained from different cantilevers have been pooled. It should be emphasized that datasets 2013 and 2014 have been obtained with a single cantilever type (MPP22220); and sometimes the same cantilever has been used for both imaging mode in air (TAP and PFT).

The large variation of reported TMV heights (Table 4) by AFM measurement illustrates the well-known phenomenon of operational aspects encountered in instrumentation (Eisenhart, 1949) and biology (Azimzadeh et al., 1992). Two studies could be compared to our work since TMV height was measured in contact or tapping mode in liquid when deposited on mica (Table 4): values of $17.2 \mathrm{~nm}$ (Zhao et al., 2008) and $18.2 \pm 1 \mathrm{~nm}$ on a calibrated system (Schabert and Rabe, 1996) were obtained which are close to our value of $17.3 \pm 0.2 \mathrm{~nm}$ (Table 3). Interestingly, another report has presented values of TMV heights obtained in different environments and revealed an average height of $12 \mathrm{~nm}$ using the contact 
Table 4

TMV height measurements in the literature.

\begin{tabular}{|c|c|c|c|c|c|}
\hline TMV height (nm) & Environment & Substrate & Imaging mode & Comments & Ref \\
\hline $19-23$ & Air & Mica & Contact & No calibration & Drygin et al. (1998) \\
\hline $17-23$ & Air & HOPG & Tapping & No calibration & Drygin et al. (1998) \\
\hline$\sim 20$ & Air & Mica/HOPG & Tapping & Estimated value from scale bar in images & Falvo et al. (1997) \\
\hline $16.8-18.6$ & Air & Glass & Tapping & Measured on aggregated viruses & Maeda (1997) \\
\hline $18.2 \pm 1$ & Liquid & Mica & Tapping & Measured by cross-sections & Schabert and Rabe (1996) \\
\hline 18 & - & HOPG & Non-contact & Measured by cross-sections, no statistics, with calibration & Knez et al. (2004) \\
\hline 17.2 & Liquid & Mica & Contact & Measured by cross-sections, single image & Zhao et al. (2008) \\
\hline 17 & Air & Blodgett film on silicon & Non-contact & No statistics & Anselmetti et al. (1994) \\
\hline 15 & Liquid & Mica & Tapping & Measured by cross-sections, no statistics, with calibration & Knez et al. (2004) \\
\hline 12 & Liquid & Gold & Contact & Measured by cross-sections, no statistics, with calibration & Knez et al. (2004) \\
\hline
\end{tabular}

mode in liquid when deposited on gold, a value of $15 \mathrm{~nm}$ when deposited on $\mathrm{MgCl}_{2}$-coated mica and imaged in liquid with the tapping mode, and a value of $18 \mathrm{~nm}$ using the non-contact mode when deposited on HOPG (Knez et al., 2004). This latter report includes a z-piezo calibration and clearly observes a correlation between increased imaging load (non-contact $<$ tapping $<$ contact) and decreased TMV height $(18 \mathrm{~nm}>15 \mathrm{~nm}>12 \mathrm{~nm})$; a conclusion which is in agreement with our studies where TMV height values are different according to various imaging conditions.

It has been suggested that discrepancy in TMV height measurements could be due to the hydration level of particles or the overall surface charge of the virion which may change depending on TMV strains (Knez et al., 2004). Hydration level has also been suggested to be responsible for height measurement discrepancies when imaging in air with the amplitude modulation (TAP) mode (Santos et al., 2012). Furthermore, it was observed that imaging in air with TAP was only possible after prolonged desiccation of the sample once deposited on mica (Thomson, 2005) which also explains why imaging isolated single molecules has been most successful at cryo-temperature in the absence of liquid water (Han et al., 1995). Our experience also shows that biological samples dried in a super-dry cabinet ( $\sim 4 \%$ relative humidity) usually provide better quality AFM images. However, in this study, extensive drying was not performed and ambient imaging (air) has been obtained with an average room humidity of $30 \%$. This hydration level is likely responsible for obtaining a height of TMV particles in air that exceeds the maximum predicted value of $19 \mathrm{~nm}$ (Table 3 and Fig. 2).

Beyond the intrinsic variation observed at the single molecule level of biological objects, the design of experimental conditions is critical to obtain reliable height values using AFM. In this study, a native TMV particle height value is expected at $19 \mathrm{~nm}$ as maximum and if this value is not observed, the TMV particles are said to be deformed. Ideally, to avoid deformation of biomolecules the theoretical AFM imaging force should be in the range of around 10 pNs per tip-sample contact (Persson, 1987). Among the eight imaging conditions, we observed that an imaging force larger than $100 \mathrm{pN}$ per tip-sample contact did not systematically generate molecule deformation. However, the largest differences in TMV height values were obtained when imaging on different substrates (almost $2 \mathrm{~nm}$ difference on mica versus SAM in air). These differences are almost constant for the datasets 2013 and 2014 even when using an identical cantilever as done for dataset 2014. Adsorption (electrostatic) forces on freshly cleaved mica are sufficiently strong to hold TMV particles for AFM imaging in air, but are likely responsible for the observed reduction in height values in air. Indeed, the impact of electrostatic interactions during adsorption on AFM substrates has been observed when depositing fibrin monomers on mica (Sit and Marchant, 2001). Besides, using simulation techniques, it was found that protein structures are either deformed or unfolded when adsorbed on mica whereas a "theoretical neutral" substrate provokes only deformation but no unfolding
(Starzyk and Cieplak, 2011). In the present study, no major unfolding or disaggregation of TMV has been observed in AFM images regardless of the tested imaging conditions (Fig. 2); however, deformation is evidenced due to the reduction in TMV height on mica with an apparent increase in TMV particle thickness although it is difficult to conclude definitely due to the tip broadening effect. It should be noted that SAM-COOH substrates are also negatively charged, although their charge density is lower than that of mica which could explain why TMV height obtained in imaging in air on SAM does not appear as strongly impacted as that observed for mica.

One of the strengths of AFM is its ability to image single molecules in physiological buffer conditions with a very high signal to noise ratio. However, there is an important trade-off when imaging isolated single molecules in liquid, i.e. the need for strong adsorption of biomolecules on the substrate. In addition, adsorbed molecules tend to dissociate from the substrate when an experiment lasts for hours and even with the soft imaging mode PFT, it is still possible to move loosely bound molecules from the substrate. Thus, to accurately image the shape of molecules in a liquid environment, single molecules must be strongly adsorbed which may lead to deformation as evidenced by reduced height as shown here when imaging TMV on mica in liquid using TAP. In a liquid environment, the difference in TMV height values obtained on mica and SAM-COOH with either PFT or TAP imaging mode is almost cancelled (Table 3 ). It is likely that water molecules reduce adsorption forces between substrates and TMV (assuming a particularly important role of electrostatic interactions) leading to a reduced binding of TMV on the substrate (mica and SAM-COOH) and consequently a reduced deformation. Such reduction in TMV binding to the substrate in liquid is consistent with the increased difficulty for imaging TMV in liquid environments (Fig. 2). One of the legitimate fears of imaging biological molecules with AFM in air is the risk of denaturation. If our underlying hypothesis is correct, i.e. a change in the TMV virus height represents physical changes in the structure of TMV, it is demonstrated in this work that the appropriate TMV virus height is also obtained when imaging the virus particle in air using an appropriate imaging mode (PFT) and appropriate substrate (Fig. 3). In this study, we confirm that SAM-COOH surface based on a ureido silylated compound is a perfect substrate that reduces biomolecule deformation even when performing AFM imaging in air (Meillan et al., 2014) and in liquid for two reasons: first, SAM-COOH surfaces have reasonably low roughness and second, it is possible to covalently bind biological molecules with softchemical treatments.

It has been suggested that PFT and TAP measurements provided similar apparent shape of surface nanobubbles (Walczyk et al., 2013); however, "true" bubble height was reached with PFT because this mode took into account the mechanical deformation of bubbles. Significant differences between height values of extracellular vesicles obtained using PFT in liquid versus those obtained using TAP in air have been observed (Hardij et al., 2013). It has 

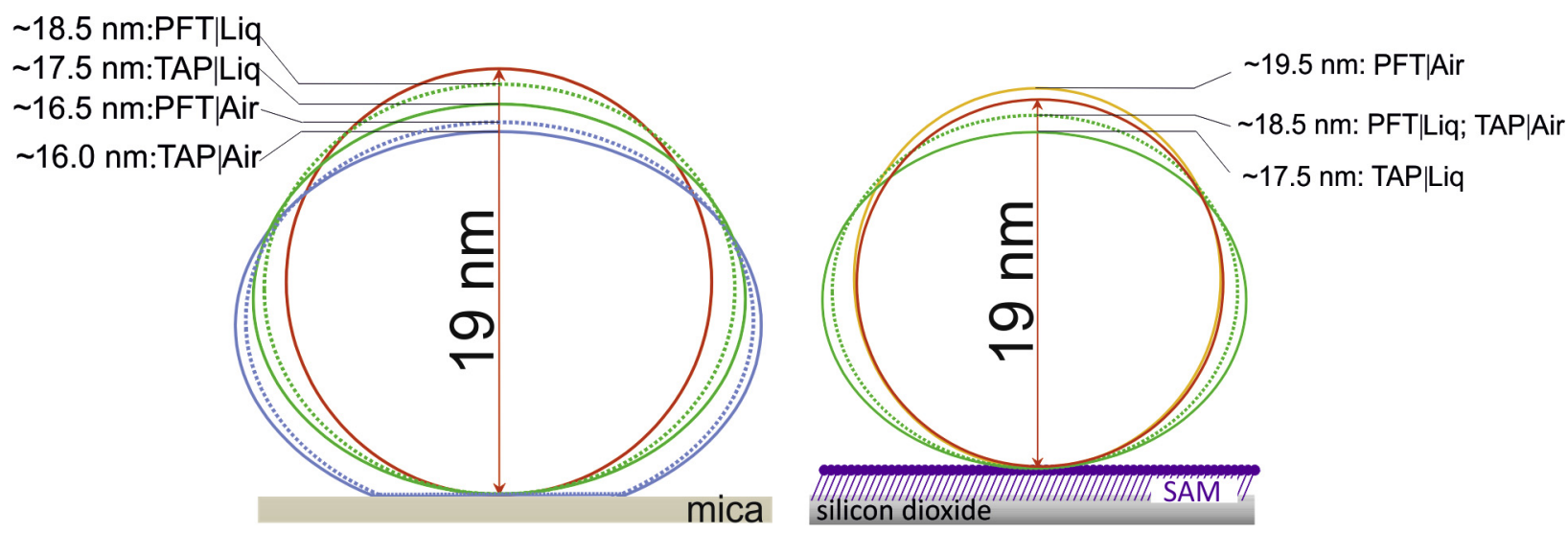

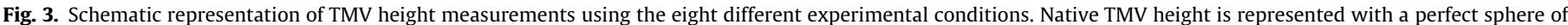

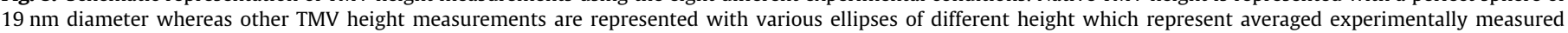

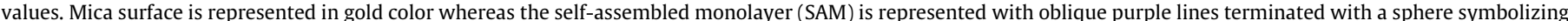

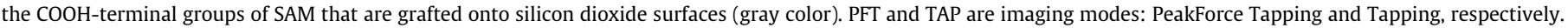

been suggested that there is an intrinsic resolution limit using the amplitude modulation (tapping) AFM imaging mode, especially when the nanoscale feature is small relative to the tip size, and that the height loss in this mode does not correlate with the sample deformation (Santos et al., 2011). According to our imaging force estimation, TAP and PFT modes use a similar imaging load. However, the off-resonance of PFT with a frequency of $2 \mathrm{kHz}$ in this study indicates that the number of tapping per imaged pixel, and consequently the total contact time, is much smaller than that of TAP at a constant scanning speed (if we assume a cantilever oscillation frequency at $100 \mathrm{kHz}$ in TAP, an imaged pixel using TAP will be hit 50 times more than that using PFT). Consequently, the difference in energy dissipation between TAP and PFT which could explain why TMV height values are systematically lower using TAP than PFT for identical substrate and imaging environment (and identical scan rate). Thus, the imaging mode contributes to the soft deformation of biological molecules, although to a lesser extent than the chemical composition of AFM substrates. Because energy dissipation occurs at each pixel, it shows that the imaging size (in pixel) and imaging speed are also critical factors when evaluating proper height of biological molecules.

For reasons explained in the introduction, TMV is an "ideal" sample to perform such detailed analyses. How are results obtained on TMV generalizable to other biomolecules? Size reduction in molecular height has been detected with AFM for a long time (Umemura et al., 1996). The origin of such a reduction in height has been attributed mostly to high-force when imaging and to substrates. To extrapolate our results to other biological molecules, we can interpret the effect in height reduction of TMV. Based on the available crystal structure, a nominal height of $19 \mathrm{~nm}$ has been defined, although in this study, we consider a "normal" TMV height to be when a value superior or equal to $18 \mathrm{~nm}$ is obtained. According to the orientation chosen in Fig. 1, a reduction of height from 19 to $18 \mathrm{~nm}$ corresponds to the crushing of a single side chain (Thr 155). The lowest height value obtained in our study $(\sim 16 \mathrm{~nm})$ would correspond to a crushing of the C-terminal loop of TMV protein (see Fig. 1). A further reduction in height would imply a crushing of the internal core of the virus particle and this was not observed in our study. Consequently, generalization of our results would suggest that depending on the experimental set-up of AFM imaging, crushing of side chains and loops are expected but not that of a tight molecular core which can be easily observed using Adepth (Chen and Pellequer, 2013) when a three-dimensional structure is known.
Finally, in metrology, instrument miscalibration is a major source of errors. Most of reported height values in AFM articles are not accompanied by a calibration statement regarding the $z$ piezo ceramique (see Table 4). Thus, it is extremely difficult to standardize height values obtained with different AFM systems on biological samples. However, even with reported calibration, variation in molecular height values still persists depending on the imaging substrate or imaging mode (see last entries of Table 4). Obviously, lack of statistics also impacts upon the correct estimation of molecular height. Most values reported in Table 4 have been obtained by a couple of cross-sections in AFM images. Consequently, another way to generalize our work on TMV is to systematically provide calibration statements and ample statistics when pursuing the goal of providing molecular height values.

\section{Conclusions}

The major conclusion in this work was that no single evaluated factor (substrate, imaging mode, imaging environment) is entirely responsible for observed perturbations in height measurement. A mica surface allows acceptable measurement of TMV height values $(>18 \mathrm{~nm}$ ) when performed in liquid but allows the worst measurements when performed in air. For TMV, and in the conditions tested in this work, imaging in air on SAM provides acceptable TMV height values. In addition, TMV height values in liquid are similar on both mica and SAM-COOH surfaces but differ with the imaging mode. Finally, the only consistent trend in our analysis was to observe systematically lower TMV height values when using TM versus PFT imaging modes.

\section{Funding}

This work was partially supported by the French ANR agency (Grant ANR-P2N-2010-NANO-003) and the French Alternative Energies and Atomic Energy Commission.

\section{Acknowledgments}

The authors would like to thank COST Action TD 1002 for supporting their networking activities. The authors would like to acknowledge Matthew Jessop (IBS Grenoble, France) for proofreading the manuscript. 


\section{References}

Afrin, R., Alam, M.T., Ikai, A., 2005. Pretransition and progressive softening of bovine carbonic anhydrase II as probed by single molecule atomic force microscopy. Protein Sci. 14, 1447-1457.

Anselmetti, D., Lüthi, R., Meyer, E., Richmond, T., Dreier, M., Frommer, J.E. Güntherodt, H.-J., 1994. Attractive-mode imaging of biological materials with dynamic force microscopy. Nanotechnology 5, 87-94.

Azimzadeh, A., Pellequer, J.L., Van Regenmortel, M.H.V., 1992. Operational aspects of antibody affinity constants measured by liquid-phase and solid-phase assays. J. Mol. Recognit. 5, 9-18.

Bergkvist, M., Carlsson, J., Karlsson, T., Oscarsson, S., 1998. TM-AFM threshold analysis of macromolecular orientation: a study of the orientation of $\operatorname{IgG}$ and IgE on mica surfaces. J. Colloid Interface Sci. 206, 475-481.

Binnig, G., Quate, C.F., Gerber, C., 1986. Atomic force microscope. Phys. Rev. Lett. 56, 930-933.

Binnig, G., Rohrer, H., Gerber, C., Weibel, E., 1982. Surface studies by scanning tunneling microscopy. Phys. Rev. Lett. 49, 57-61.

Chaves, R.C., Pellequer, J.-L., 2013. DockAFM: benchmarking protein structures by docking under AFM topographs. Bioinformatics 29, 3230-3231.

Chaves, R.C., Dahmane, S., Odorico, M., Nicolaes, G.A.F., Pellequer, J.-L., 2014. Factor Va alternative conformation reconstruction using Atomic Force Microscopy. Thromb. Haemost. 112, 1167-1173.

Chen, S.-w.W., Pellequer, J.L., 2011. DeStripe: frequency-based algorithm for removing stripe noises from AFM images. BMC Struct. Biol. 11, 7.

Chen, S.-w.W., Pellequer, J.L., 2013. Adepth: new representation and its implications for atomic depths of macromolecules. Nucl. Acids Res. 41, W412-W416.

Chen, S.-w.W., Teulon, J.M., Godon, C., Pellequer, J.-L., 2016. Atomic force microscope, molecular imaging, and analysis. J. Mol. Recognit. 29, 51-55.

Chen, S.-W.W., Odorico, M., Meillan, M., Vellutini, L., Teulon, J.-M., Parot, P., Bennetau, B., Pellequer, J.-L., 2013. Nanoscale structural features determined by AFM for single virus particles. Nanoscale 22, 10877-10886.

Cheung, J.W., Walker, G.C., 2008. Immuno-atomic force microscopy characterization of adsorbed fibronectin. Langmuir 24, 13842-13849.

Costa, L., Andriatis, A., Brennich, M., Teulon, J.-M., Chen, S.W.W., Pellequer, J.-L., Round, A., 2016. Combined small angle X-ray solution scattering with atomic force microscopy for characterizing radiation damage on biologica macromolecules. BMC Struct. Biol. 16, 18.

Creager, A.N.H., 2002. The Life of a Virus: Tobacco Mosaic Virus as an Experimental Model. The University of Chicago Press, Chicago. 1930-1965.

Czajkowsky, D.M., Shao, Z., 2009. The human IgM pentamer is a mushroom-shaped molecule with a flexural bias. Proc. Natl. Acad. Sci. U.S.A. 106, 14960-14965.

Drygin, Y.F., Bordunova, O.A., Gallyamov, M.O., Yaminsky, I.V., 1998. Atomic force microscopy examination of tobacco mosaic virus and virion RNA. FEBS Lett. 425, 217-221.

Eisenhart, C., 1949. Operational aspects of instrument design. Science 110, 343-346.

Falvo, M.R., Washburn, S., Superfine, R., Finch, M., Brooks Jr., F.P., Chi, V., Taylor 2nd, R.M., 1997. Manipulation of individual viruses: friction and mechanical properties. Biophys. J. 72, 1396-1403.

Han, W., Mou, J., Sheng, J., Yang, J., Shao, Z., 1995. Cryo atomic force microscopy: a new approach for biological imaging at high resolution. Biochemistry 34, 8215 8220.

Hardij, J., Cecchet, F., Berquand, A., Gheldof, D., Chatelain, C., Mullier, F., Chatelain, B., Dogne, J.M., 2013. Characterisation of tissue factor-bearing extracellular vesicles with AFM: comparison of air-tapping-mode AFM and liquid Peak Force AFM. J. Extracell. Vesicles 2, 21045.

He, J., Wang, J., Hu, J., Sun, J., Czajkowsky, D.M., Shao, Z., 2016. Single molecule atomic force microscopy of aerolysin pore complexes reveals unexpected starshaped topography. J. Mol. Recognit. 29, 174-181.

Horne, R.W., Hobart, J.M., Markham, R., 1976. Electron microscopy of tobacco mosaic virus prepared with the aid of negative staining-carbon film techniques. J. Gen. Virol. 31, 265-269.

Humphrey, W., Dalke, A., Schulten, K., 1996. VMD: visual molecular dynamics. J. Mol. Graph. 14, 33-38.

Kaemmer, S.B., 2011. Introduction to Bruker's ScanAsyst and PeakForce Tapping AFM technology. Bruker Application Note \#133, Santa Barbara.

Knez, M., Sumser, M.P., Bittner, A.M., Wege, C., Jeske, H., Hoffmann, D.M., Kuhnke, K. Kern, K., 2004. Binding the tobacco mosaic virus to inorganic surfaces. Langmuir 20, 441-447.

Maeda, H., 1997. An atomic force microscopy study for the assembly structures of tobacco mosaic virus and their size evaluation. Langmuir 13, 4150-4161.

Marti, O., Drake, B., Hansma, P.K., 1987. Atomic force microscopy of liquid-covered surfaces: atomic resolution images. Appl. Phys. Lett. 51, 484-486.

Meillan, M., Ramin, M., Buffeteau, T., Marsaudon, S., Odorico, M., Chen, S.-w.W. Pellequer, J.-L., Degueil, M., Heuze, K., Vellutini, L., Bennetau, B., 2014. Selfassembled monolayer for AFM measurements of Tobacco Mosaic Virus (TMV) at the atomic level. RSC Adv. 4, 11927-11930.

Moreno-Herrero, F., Colchero, J., Baro, A.M., 2003. DNA height in scanning force microscopy. Ultramicroscopy 96, 167-174.

Namba, K., Stubbs, G., 1986. Structure of tobacco mosaic virus at $3.6 \AA$ resolution: implications for assembly. Science 231, 1401-1406.
Namba, K., Pattanayek, R., Stubbs, G., 1989. Visualization of protein-nucleic acid interactions in a virus. Refined structure of intact tobacco mosaic virus at $2.9 \AA$ resolution by X-ray fiber diffraction. J. Mol. Biol. 208, 307-325.

Nečas, D., Klapetek, P., 2012. Gwyddion: an open-source software for SPM data analysis. Cent. Eur. J. Phys. 10, 181-188.

Pattanayek, R., Stubbs, G., 1992. Structure of the U2 strain of tobacco mosaic virus refined at 3.5 A resolution using X-ray fiber diffraction. J. Mol. Biol. 228, 516528.

Persson, B.N.J., 1987. The atomic force microscope: can it be used to study biological molecules? Chem. Phys. Lett. 141, 366-368.

Pfreundschuh, M., Martinez-Martin, D., Mulvihill, E., Wegmann, S., Muller, D.J., 2014. Multiparametric high-resolution imaging of native proteins by forcedistance curve-based AFM. Nat. Protoc. 9, 1113-1130.

Radmacher, M., Fritz, M., Cleveland, J.P., Walters, D.A., Hansma, P.K., 1994. Imaging adhesion forces and elasticity of lysozyme adsorbed on mica with the atomic force microscope. Langmuir 10, 3809-3814.

Ramin, M.A., Le Bourdon, G., Heuze, K., Degueil, M., Buffeteau, T., Bennetau, B., Vellutini, L., 2015. Epoxy-terminated self-assembled monolayers containing internal urea or amide groups. Langmuir 31, 2783-2789.

Ramin, M.A., Le Bourdon, G., Heuze, K., Degueil, M., Belin, C., Buffeteau, T., Bennetau, B., Vellutini, L., 2012. Functionalized hydrogen-bonding self-assembled monolayers grafted onto $\mathrm{SiO}(2)$ substrates. Langmuir 28, 17672-17680.

San Paulo, A., Garcia, R., 2000. High-resolution imaging of antibodies by tappingmode atomic force microscopy: attractive and repulsive tip-sample interaction regimes. Biophys. J. 78, 1599-1605.

San Paulo, A., Garcia, R., 2001. Tip-surfaces forces, amplitude, and energy dissipation in amplitude-modulation force microscopy. Phys. Rev. B 64, 193411.

Santos, S., Verdaguer, A., Chiesa, M., 2012. The effects of adsorbed water layers on the apparent height of nanostructures in ambient amplitude modulation atomic force microscopy. J. Chem. Phys. 137, 044201.

Santos, S., Barcons, V., Christenson, H.K., Font, J., Thomson, N.H., 2011. The intrinsic resolution limit in the atomic force microscope: implications for heights of nano-scale features. PLoS ONE 6, e23821.

Schabert, F.A., Engel, A., 1994. Reproducible acquisition of Escherichia coli porin surface topographs by atomic force microscopy. Biophys. J. 67, 2394-2403.

Schabert, F.A., Rabe, J.P., 1996. Vertical dimension of hydrated biological samples in tapping mode scanning force microscopy. Biophys. J. 70, 1514-1520.

Scheuring, S., Boudier, T., Sturgis, J.N., 2007. From high-resolution AFM topographs to atomic models of supramolecular assemblies. J. Struct. Biol. 159, 268-276.

Sit, P.S., Marchant, R.E., 2001. Surface-dependent differences in fibrin assembly visualized by atomic force microscopy. Surf. Sci. 491, 421-432.

Spatz, J.P., Sheiko, S., Moller, M., Winkler, R.G., Reineker, P., Marti, O., 1995. Forces affecting the substrate in resonant tapping force microscopy. Nanotechnology 6 , $40-44$.

Starzyk, A., Cieplak, M., 2011. Denaturation of proteins near polar surfaces. J. Chem. Phys. 135, 235103.

Thomson, N.H., 2005. Imaging the substructure of antibodies with tapping-mode AFM in air: the importance of a water layer on mica. J. Microsc. 217, 193-199.

Trinh, M.-H., Odorico, M., Bellanger, L., Jacquemond, M., Parot, P., Pellequer, J.-L., 2011. Tobacco mosaic virus as an AFM tip calibrator. J. Mol. Recognit. 24, $503-$ 510.

Trinh, M.-H., Odorico, M., Pique, M.E., Teulon, J.-M., Roberts, V.A., Ten Eyck, L.F., Getzoff, E.D., Parot, P., Chen, S.-W.W., Pellequer, J.-L., 2012. Computational reconstruction of multidomain proteins using atomic force microscopy data. Structure 20, 113-120.

Umemura, K., Sutoh, K., Tokunaga, F., Kataoka, M., Kamikubo, H., Arakawa, H., Ikai, A., 1996. The structure difference of proteins isolated on substrate with different techniques as studied by the atomic force microscope. Scanning 18 $275-280$.

Villarrubia, J.S., 1997. Algorithms for scanned probe microscope image simulation, surface reconstruction, and tip estimation. J. Res. Natl. Inst. Stand. Technol. 102, 425-454.

Walczyk, W., Schon, P.M., Schonherr, H., 2013. The effect of PeakForce tapping mode AFM imaging on the apparent shape of surface nanobubbles. J. Phys.: Condens. Matter 25, 184005.

Yang, C.-W., Hwang, I.-S., Chen, Y.F., Chang, C.S., Tsai, D.P., 2007. Imaging of soft matter with tapping-mode atomic force microscopy and non-contact-mode atomic force microscopy. Nanotechnology 18, 084009.

Zenhausern, F., Adrian, M., ten Heggeler-Bordier, B., Ardizzoni, F., Descouts, P., 1993. Enhanced imaging of biomolecules with electron beam deposited tips for scanning force microscopy. J. Appl. Phys. 73, 7232-7237.

Zenhausern, F., Adrian, M., Emch, R., Taborelli, M., Jobin, M., Descouts, P., 1992. Scanning force microscopy and cryo-electron microscopy of tobacco mosaic virus as a test specimen. Ultramicroscopy 42-44, 1168-1172.

Zhao, Y., Ge, Z., Fang, J., 2008. Elastic modulus of viral nanotubes. Phys. Rev. E Stat. Nonlin. Soft Matter Phys. 78, 031914.

Zhong, Q., Inniss, D., Kjoller, K., Elings, V., 1993. Fractured polymer/silica fiber surface studied by tapping mode atomic force microscopy. Surf. Sci. Lett. 290, L688-L692. 